$10-1-2006$

\title{
How Does a Child with Sensory Processing Problems Play?
}

Jeryl D. Benson

Duquesne University

Meghana N. Nicka

Duquesne University

Perri Stern

Duquesne University

Follow this and additional works at: https://nsuworks.nova.edu/ijahsp

Part of the Medicine and Health Sciences Commons

\section{Recommended Citation}

Benson JD, Nicka MN, Stern P. How Does a Child with Sensory Processing Problems Play?. The Internet Journal of Allied Health Sciences and Practice. 2006 Oct 01;4(4), Article 4.

This Manuscript is brought to you for free and open access by the College of Health Care Sciences at NSUWorks. It has been accepted for inclusion in Internet Journal of Allied Health Sciences and Practice by an authorized editor of NSUWorks. For more information, please contact nsuworks@nova.edu. 


\title{
How Does a Child with Sensory Processing Problems Play?
}

\begin{abstract}
The occupation of play during one's childhood years serves as a foundation for the development of future occupations in an individual's life. By understanding a child's extant play skills and deficits, one may then provide the necessary interventions needed to promote development and successful growth into new occupations. The purpose of this paper was to understand how a child with sensory processing deficits plays in a naturalistic environment. The findings revealed an interplay between the child's underlying sensory processing deficits and his play skills and behaviors. Increased understanding of how a child with sensory processing deficits plays will provide information for other occupational therapists and help in the treatment of children with similar deficits.
\end{abstract}




\section{IJAAHSP \\ The Internet Jourfal of Allied Health Sciences and Practice \\ http://ijahsp.nova.edu}

A Peer Reviewed Publication of the College of Allied Health \& Nursing at Nova Southeastern University

Dedicated to allied health professional practice and education

http://ijahsp.nova.edu Vol. 4 No. 4 ISSN 1540-580X

\section{How Does a Child with Sensory Processing Problems Play?}

\section{Jeryl D. Benson, MS, OTR/L, BCP. ${ }^{1} \quad$ Meghan N. Nicka, MOT, OTR/L. ${ }^{2} \quad$ Perri Stern, Ed.D, OTR. ${ }^{3}$}

1. Instructor, Occupational Therapy Department, Duquesne University

2. Occupational Therapist, East Tennessee Children's Hospital

3. Associate Professor, Occupational Therapy Department, Duquesne University

\section{Citation:}

Benson, J. Nicka, M., Stern, P. How does a child with sensory processing problems play? The Internet Journal of Allied Health Sciences and Practice. October 2006. Volume 4 Number 4.

\section{Abstract}

The occupation of play during one's childhood years serves as a foundation for the development of future occupations in an individual's life. By understanding a child's extant play skills and deficits, one may then provide the necessary interventions needed to promote development and successful growth into new occupations. The purpose of this paper was to understand how a child with sensory processing deficits plays in a naturalistic environment. The findings revealed an interplay between the child's underlying sensory processing deficits and his play skills and behaviors. Increased understanding of how a child with sensory processing deficits plays will provide information for other occupational therapists and help in the treatment of children with similar deficits.

\section{Introduction}

Many therapists consider play to be a child's primary occupation during the early years of life. ${ }^{1,2}$ In 1949, N.A. Alessandrini defined play as,

"A child's way of learning and an outlet for his innate need of activity. It is his business or career. In it he engages himself with the same attitude and energy that we engage ourselves in our regular work. For each child it is a serious undertaking not to be confused with diversion or idle use of time. Play is not folly. It is purposeful activity." 3

A more contemporary view of play includes the components of internal and external motivation, safe, spontaneous and active engagement in the play process, direction and decisions of the play experience being controlled by the child, and interaction with the environment.4-6

Many occupational therapists feel that the common themes in play, which include intrinsic motivation, internal reality, and internal locus of control are needed for a child to engage in playful behaviors and interactions.3,4,7,8 When these are present, a child is self-motivated to engage in a play activity, is free from rules, procedures or guidelines to follow during the play, and is able to self-direct play. ${ }^{2}$

Intrinsic motivation during play is evidenced when a child "engage[es] in an activity because something about the activity itself is appealing, rather than because someone else told the [child] to do it or for some gain outside of the process itself." 9 Examples of identified motivators that may cause a child to find an activity appealing include social interaction with others, competition with siblings, friends and parents, and sensory stimulation.

Bundy also describes the theme of internal reality as the child "choos[ing] how close to objective reality the transaction will be." 9 This area of play requires a child to have the capability to take a play activity or task and engage in pretend or fantasy play.,9-11 Pretend play allows the child to maintain control of the play situation and modify the demands of the activity to eliminate the pressure to perform. The child must also have the ability to reduce any consequences of a play activity that might be normally 
associated with that activity in reality. 4,9

Bundy defines internal locus of control as the child's being 'largely 'in charge' of his or her actions and at least some aspects of the activity's outcome." 4 When a child is able to act on their motivation to engage in a play activity, they are able to determine the factors of the experience. For example, they determine who, what, where, and how they will play. As a result, they are then free to suspend the constraints of reality and maintain an internal control of the situation. Through active participation in play, a child is able to interact and explore his or her environment. This allows for increased "socialization, creativity, language development, problem-solving abilities, and sensorimotor skills", resulting in the ability to establish and achieve adult occupations. ${ }^{7}$

\section{Play as an Occupational Therapy Intervention}

Many occupational therapists use play as a therapeutic modality, to increase a child's play skills or to facilitate playful behaviors in a child.2,12 Play bridges the gap between childhood and adult occupational behavior. ${ }^{13}$ If a child has a deficit in his or her ability to be intrinsically motivated, to suspend reality, to have an internal locus of control, to be happy, energetic or playful, or has an inability to process sensory information from play experiences, then a child's development may be stifled. It is important for occupational therapists to help children increase their play skills and promote generalization and transfer of skills to future occupations in life.

Stagnitti \& Unsworth suggest that a child with limited play, for example pretend play, may have limitations with participation in daily life. 5 They suggest that these limitations may have social, emotional and cognitive consequences; therefore, potentially limiting engagement with peers and inclusion in their communities. ${ }^{5,14}$

\section{Sensory Integration and Play}

Ayres defines sensory integration as the "organization of sensation for use" of purposeful activity. ${ }^{15}$ A child who is engaged in an activity processes and organizes the sensory input he or she is receiving from the environment to make an "adaptive response" which allows them to achieve his or her desired goal. ${ }^{15}$

Many children have difficulty integrating sensations. These difficulties are often classified under the overall umbrella of sensory integration disorders. One such disorder involves sensory modulation problems which are manifested in a child's inability to "generate responses that are appropriately graded in relation to incoming sensory stimuli, rather than underreacting or overreacting to them". ${ }^{15}$ Another disorder may involve sensory registration deficits, whereby a child fails to focus his or her attention to stimuli within the environment. ${ }^{15}$ Ayres believed that in order for a child to organize and process sensory information that the "sensory systems [must] function synergistically with each other rather than in isolation."15 The presence of a sensory integration disorder may in turn, cause conflict and difficulty for a child in activities of daily living, school, play, social interaction, or other childhood occupations.

Sensory integration disorders may also result from a child having lived in an impoverished environment.16 "Adequate nutrition, social stimulation or interaction, 'tender, loving care,' and active exploration of the environment" are essential. Children enhance their development through active exploration of the environment, manipulation of materials, toys, and other physical stimuli. If a child has "missed the opportunity for the touch, smell, position sense, and sight provided by a primary caregiver during feeding time," the child has been deprived of tactile and kinesthetic input possibly causing developmental delays. ${ }^{16}$ Provence and Lipton assert that a variety of sensory stimulation opportunities are necessary to enable a child to enhance his or her repertoire of experiences and organize external stimuli. ${ }^{17}$

Couch, Deitz, \& Kanny note that "in sensory integration, play is used as a treatment medium and motivator to promote organization of sensory information."18 In addition, "play is also used in occupational therapy, including sensory integration treatment, as a context in which to elicit change." The authors documented evidence of this change and described how parents "reported changes in their children's performance" as a result of intervention using a sensory integrative approach.8,19 Anderson reported that using sensory integration improved a child's "willingness to try new play activities, socialization with other children, and ability to express emotions and desires." 19

\section{Purpose of the Study}

The purpose of this study was to understand how a child with sensory processing deficits plays in a naturalistic environment. Understanding the play skills and play behaviors of a child with sensory processing deficits in a naturalistic environment may enhance the therapist's ability to provide intervention activities that promote a child's optimal occupational performance. Increased understanding of how a child with sensory processing deficits plays will provide information for other occupational therapists and help in the treatment of children with similar deficits.

\section{Methods}

This single case pilot study occurred between April 2003 and June 2003. The participant was a client at a combined Speech-Language Pathology / Occupational Therapy clinic that operates within a mid-sized university in the northeastern United States. An occupational therapy 
academic faculty member provides and supervises intervention at the clinic. At the time of the study, the child was 6 years old and was enrolled in a public school kindergarten in an affluent suburb. He had been referred to the clinic for an occupational therapy evaluation secondary to his having "school difficulties." The parents sought occupational therapy intervention to enhance his school occupations.

Elijah (a pseudonym) had been diagnosed with developmental delay and motor coordination difficulties. He was adopted from Russia at 9 months of age and lives with his parents and older brother. Relevant medical history includes surgery in January 2003 to correct misalignment of his eyes which was contributing to writing difficulties. After his surgery, Elijah's mother noticed that his writing was still impaired, and as a result, sought occupational therapy evaluation and intervention. Elijah was treated at the Clinic once per week from January 2003 through June 2003.

The occupational therapy evaluation revealed that Elijah had difficulties with a variety of occupations including play, self care, and leisure. It was determined that his challenges with his childhood occupations were greatly influenced by sensory processing deficits. The "Sensory Profile Questionnaire" completed by Elijah's mother indicated a probable difference in his low endurance/tone and sensory processing related to endurance/tone. ${ }^{20}$ Winging of the scapula during upper extremity weight bearing, an immature writing grasp, and a "soft" tone in his hands were also noted. Vestibular processing deficits included difficulty crossing midline, difficulty maintaining an upright position when his center of gravity was displaced, and the presence of associated mouth movements during cutting and balancing activities. In addition, Elijah's arousal level was easily increased when he received vestibular input. This was evident in his need for constant movement, which seemed to help him re-focus on tasks. Proprioceptive deficits were indicated by Elijah's need to constantly fall on the floor and crash into obstacles in the environment.

Elijah received occupational therapy services to address his affected occupations with intervention impacting occupational engagement in self-care, feeding and handwriting. Treatment for the above noted deficits in vestibular and proprioceptive processing, attention/behavior control, visual perceptual skills, and fine motor skills were embedded into the occupation of play and work. In addition to participating in occupational therapy intervention sessions, the parents gave their informed, written consent for their child to participate in the research study. Elijah gave his written assent to participate.

Elijah participated in two videotaped, 45-minute free play sessions within his home. During both of the free play sessions, his play choices were self-directed, with social interaction from his mother or the interviewer occurring only when he sought their attention. Elijah's mother participated in two 45 minute semi-structured interviews while her child was playing and being videotaped. After the first free play/interview session, the second author reviewed the videotape and audio-taped parent interview to note initial observations and concerns and to identify areas to further explore during the second session.

Documentation and records from the clinic were also reviewed. These documents included the occupational therapy evaluation and the Sensory Profile Caregiver Questionnaire.20 The Sensory Profile established a baseline of the child's sensory processing strengths and limitations as indicated by the child's mother.

A two-phase content analysis was used to organize and synthesize the data collected from the videotapes, interviews, and documents. Data from each source were first analyzed separately and reviewed for themes that emerged regarding the child's play. The individual themes that emerged from each individual source were then synthesized and combined to produce a comprehensive analysis of the data.

\section{Phase 1}

The videotapes of the free play sessions were reviewed several times. Observations were recorded on a "Play Observation Checklist" (Appendix A). Each video was divided into a series of "play segments." A play segment was defined by the length of time the child spent on a play activity before he switched to another activity. Elijah's play segments lasted between 2 and 5 minutes. The first and second authors independently coded the videos and recorded observations according to 4 categories that had been determined a priori: 1) how often the child used each sensory system during the play activity, 2) the child's level of emotional involvement in the play activity, 3) the child's level of independence in setting up and playing during the activity and 4) the type of play category observed. ${ }^{2}$

The two parent interviews were transcribed verbatim and were also analyzed according to the content analysis procedures described above to determine themes that emerged during the two interviews.

We also used the information from the "Sensory Profile Questionnaire" and the initial evaluation and progress notes from occupational therapy treatment sessions at the Clinic to determine themes. ${ }^{20}$ Analysis of the "Sensory Profile Questionnaire" followed the standardized procedures as discussed in the assessment manual. ${ }^{20}$ Analysis of the initial evaluation and progress notes occurred in a way that was similar to the analysis of the interview transcripts. 


\section{Phase 2}

The second phase of the data analysis consisted of reviewing the data from the play sessions, interviews, and clinical documents all together to synthesize the themes that had emerged from each of the three sources.

Trustworthiness was addressed by using several procedures, including member checking, peer debriefing, maintaining an audit trail, and triangulating data. The parent was provided with a written transcript of the interview to review and correct any inaccuracies and an initial interpretation of the data. The first author, an experienced pediatric specialist, served as a peer debriefer throughout the process. Data were collected via three methods and were first analyzed independently and then together by two investigators. An audit trail of all study documents has been maintained.

\section{Results}

The 2 phase content analysis, including the analysis of the parent interview, the videotaped play sessions, and the review of intervention documentation yielded six themes that described how Elijah played. The themes included: a limited play repertoire, modified/cautious play, attention, emotional investment, sensory seeking play, and immature play level. In addition, the parent interview revealed a sense that Elijah's play skills affected his social relationships in school and at home.

\section{Limited Play Repertoire}

Elijah appears to have a more limited play repertoire than is typical for children his age. Although Elijah has a vast array of toys and options for play at home, he does not utilize the context as would be expected. Elijah continuously engages in the same play choices, participating in fine motor activities that require eye-hand coordination and precision such as cutting and pasting, coloring, assembling books with construction paper, and drawing. These activities result in the same types of projects that have previously been introduced in school. Elijah's mother noted he often participates at home in activities, such as the ones identified above, that he often becomes "frustrated with at school" (oral communication, May 29, 2003). He often pretends to be a teacher, assigning projects to his "class." These behaviors are "safe" for Elijah; they are familiar and have been designed and implemented by others.

Elijah's participation in gross motor play was consistent with his fine motor play in that he participated in only a few, select gross motor activities during the free play sessions. These activities included playing on a swing-set on the slide, climbing up the ladder, and swinging, participating in a pretend play activity of "Lord of the Rings," riding his scooter, and playing basketball. These play choices are all familiar activities that Elijah participates in on a regular basis. Although many other choices were available, Elijah did not pursue them.

\section{Modified/Cautious Play}

Elijah is cautious about going beyond the typical boundaries of any given play activity. He seems to modify his behavior to decrease the challenge within the task requirements so that he does not exceed his skill level. For example, while riding a scooter, Elijah consistently started and stopped the scooter with his foot to slow it down, and crashed the scooter into the grass when he became uncomfortable with riding the scooter on a flat pavement.

\section{Poor Attention}

Children display different levels of attention to play activities, usually depending on the child's age and the task involved. Although there is variability, it is not unusual for a 6 year old child to engage in a preferred activity for up to one hour. ${ }^{21}$ Some children become highly involved in the play activity and demonstrate a higher level of imagination and creativity. Elijah demonstrates a short attention span and little active involvement in a play activity. For example, he engages in activities for only two to five minutes. This brief engagement does not reflect the more advanced imagination that would be considered typical for a child his age.

\section{Minimal Emotional Investment}

Children demonstrate increasing levels of emotional involvement in play as they engage in occupations that are motivating. Elijah did not appear to be emotionally invested during play. He often appeared bored, disengaged, and uninterested in the play activities. He participated in the same play choices over and over again. And, when he encountered a challenge within a self-selected play activity, Elijah was critical of his abilities, stating "I'm so stupid, stupid, stupid."

\section{Sensory Seeking Play}

"He jumps off of everything; whenever we are outside he is jumping off everything. Jumping till he falls down, jumping till he falls off his bed, gets bruises... He'll hurt himself, he'll bruise himself or you know because it's like he's not very graceful... All he would do is walk and slam down on his knees, he would be walking and fall down on his knees... But not like he would do it on purpose but do it really hard and make us nervous... For a long time he did that and we would say don't do that, don't do that. He would slam down so hard his knees were bruised." (oral communication, May 29, 2003)

Elijah constantly seeks an abundance of sensory input from the environment He seeks more vestibular and proprioceptive input within play than would typically be 
needed. This seemed to affect his ability to engage in various activities. As noted above, he seems to create the opportunity for movement, even when not expected.

\section{Developmental Level of Play}

Takata suggests that the developmental sequence of play is predictable. ${ }^{3}$ Phases of play can be put into categories that describe the type of play in which the child engages. Sensorimotor play occurs between birth and 2 years, symbolic play is evident between ages 2 and 4. Dramatic and complex play are evident at age 4 to 7 , after which more complex play skills develop and continue through adolescence. 2,3

Elijah often participates in play activities at a symbolic play level; he plays with objects and materials in a manner they are designed to be played with. He does not participate in creative play which would be evidenced by a more sophisticated interaction with the play object. For example, while playing with a cape, Elijah put on the cape and ran around his bed a few times with it, jumped up and down with it on, and spun around. This reflects symbolic play because he was playing with the cape at its most basic level. Creative play would have been evident had Elijah taken the cape, created a make-believe story and acted it out with the cape.

This symbolic play style is seen in other activities, for example his playing on the swing-set, with stuffed animals, and in arts and crafts activities. Elijah did demonstrate some creative play while pretending "Lord of the Rings." He used a stick to pretend that he was fighting off "the enemy," attacking oncoming enemies and hiding from them. However, it should be noted that Elijah was a fan of the movie "Lord of the Rings" and it appeared he was merely mimicking what he observed and not acting on his own ideas.

\section{Impact on Peer and Social Relationships}

Although not observed during the free play sessions, Elijah's mother reported that he struggles with social interactions with other children. The same emotional behaviors, limited play choices, and low self-esteem, appear to also be evident at school. For example, Elijah has difficulty participating in a part of the day called "center time" (oral communication, May 29, 2003), an activity that allows for social interaction between classmates. Elijah's mother describes this experience as follows:

"Center time is when a few children go to different stations and they're supposed to play together. They would ask him to play and he would say no. [Activities they participated in] were things like puzzles, arts and crafts. Now that I think about it, it totally makes sense to me. It was things that he would have had to feel a deficit." (oral communication, May 29, 2003)

Elijah's mother does note that he interacts and engages well with other children in areas of strength for him such as reading and "playing teacher." Also consistent is his difficulty with gross motor activities at school. During these activities he seems "awkward," becomes frustrated, and reacts by having a tantrum of "screeching and crying until [the other children] try [to] accommodate him" (oral communication, May 29, 2003).

\section{Discussion}

The purpose of this case study was to understand how a child with sensory processing deficits plays in a naturalistic environment. The findings revealed an interplay between the child's underlying sensory processing deficits and his play skills and behaviors. The poor attention, sensory seeking behaviors, and caution during tasks that were evident in his everyday school and self care occupations were also evident in play. Elijah demonstrated a limited play repertoire that seemed to result in a more limited set of play experiences than would be expected for a child his age. These deficits interfered with the developmental progression of his play skills. Ultimately, they impacted not just the occupation of play, but also his social engagement and emotional investment in his occupations.

Smyth \& Anderson found that most children with developmental coordination disorders are less active in group play situations than typical developing children. ${ }^{22}$ Children with developmental coordination disorders opt instead to play alone or watch other children play. By choosing a more solitary style of play, children with disabilities end up isolating themselves and perpetuating the cycle of delayed development. This is evident in play skills, social engagement, and participation in overall childhood occupations. Poulsen \& Ziviani encourage occupational therapists to "identify the activities and conditions that support occupational engagement in physically active pursuits for children" as the first step to intervention planning. ${ }^{23}$

The child's insufficient emotional investment may reflect a lack of pleasure gained from the interaction. This may result in less motivation to further explore the potential of a play occupation, and again, contribute to a cycle of delay. Bober, Humphry, Carswell \& Core discuss the impact of motivation on play. ${ }^{24}$ They state that motivation is related to persistence and "persistence toward a goal ensures practice and potentially affects the emerging quality of the performance in play". ${ }^{24}$ Although this child did demonstrate persistence with mastered skills, we saw little evidence of persistence towards a goal or new dimension of an existing occupation.

As occupational therapists we have an obligation to work

C The Internet Journal of Allied Health Sciences and Practice, 2006 
with our clients holistically, and to promote emerging occupations and their essential qualities including performance, engagement and motivation. Implications for this case study are three fold:

1) Understanding how a child with a sensory processing problem plays will better inform the occupational therapist when developing the intervention plan.

2) As self confidence increased so did mastery motivation resulting in improved occupational performance and

3) Improved occupational performance then impacted his social interactions and engagement.

\section{Conclusion}

This case study provided a glimpse into the play life of a child with sensory processing deficits. "Some individuals who have sensory integrative dysfunction may also have difficulty playing," as is evident in the case of Elijah. ${ }^{9}$ After examining the components of play and Elijah's play style, one can see that initially his play style fell more on the nonplayful side of the continuum. For example, in many of his gross motor play activities he went through the motions of the play task and had limited play choices, often appearing disengaged and distracted.

The occupation of play during one's childhood years serves as a foundation for the development of future occupations in an individual's life. Occupational therapists may find this information beneficial when setting goals and developing intervention plans for children who have sensory processing deficits that are similar to Elijah's. By understanding a child's extant play skills and deficits, one may then provide the necessary interventions needed to promote development and successful growth into new occupations.

\section{References}

1. Bazyk S, Stalnaker D, Llerena M, Ekelman B, \& Bazyk J. Play in Mayan children. The American Journal of Occupational Therapy. 2003; 57: 273-283.

2. Morrison CD \& Metzger P. Play. In Case-Smith J. ed. Occupational Therapy for Children. St. Louis: Mosby; 2001.

3. Parham LD \& Primeau LA. Play and Occupational Therapy. In Parham DL \& Fazio LS. ed. Play in Occupational Therapy for Children. St. Louis: Mosby; 1997.

4. Bundy AC. Play and Playfulness: What to Look For. In Parham DL \& Fazio LS ed. Play in Occupational Therapy for Children. St. Louis: Mosby; 1997.

5. Stagnitti K \& Unsworth C. The importance of pretend play in child development: An occupational therapy perspective. The British Journal of Occupational Therapy. 2000; 63: 121-127.

6. Stagnitti K, Unsworth C, \& Rodger S. Development of an assessment to identify play behaviours that discriminate between the play of typical preschoolers and preschoolers with pre-academic problems. The Canadian Journal of Occupational Therapy. 2000; 67: 291-303.

7. Cooper RJ. The impact of child abuse on children's play. Occupational Therapy International. 2000; 7: 259-276.

8. Cross LA \& Coster WJ. Symbolic play language during sensory integration treatment. The American Journal of Occupational Therapy. 1997; 51:808-814.

9. Bundy AC. Play Theory and Sensory Integration. In Bundy AC, Lane SJ, \& Murray EA ed. Sensory Integration Theory and Practice-2nd Ed. Philadelphia: FA Davis; 2002: 227-240.

10. Rubin K, Fein GG, \& Vandenber B. Play. In P. H. Mussen ed. Handbook of child psychology: Vol.4. Socialization personality and social development $4^{\text {th }}$ ed. New York: Wiley; 1983: 693-774.

11. Sawyer RK. Pretend play as improvisation: Conversation in the preschool classroom. Mahwah, NJ: Lawrence Erlbaum Associates; 1997.

12. Saunders I, Sayer M, \& Goodlae A. The relationship between playfulness and coping in preschool children: A pilot study. The American Journal of Occupational Therapy. 1999; 53: 221-226.

13. Reilly M. Play as exploratory learning. Beverly Hills: Sage Publications; 1974

14. Cohn E, Miller LJ, \& Tickle-Degnen L. Parental hopes for therapy outcomes: Children with sensory modulation disorders. The American Journal of Occupational Therapy. 2000; 54:36-43.

15. Parham LD \& Mailloux Z. Sensory Integration. In Case Smith, J. ed. Occupational Therapy for Children. St. Louis: Mosby; 2001: 329-381.

16. Cermak SA. The effects of deprivation on processing, play, and praxis. In Roley E, El Blanche SS, \& Schaaf RC ed. Understanding the Nature of Sensory Integration with Diverse Populations. United States: Therapy Skill Builders; 2001: 385-408.

17. Provence S \& Lipton RC. Infants in institutions: A comparison of their development with family-reared infants during the first year of life. New York: International Universities Press; 1962.

18. Couch KJ, Deitz JC, \& Kanny EM. The role of playing pediatric occupational therapy. The American Journal of Occupational Therapy. 1998; 52:111-117.

19. Cohn ES. Parent perspectives of occupational therapy using a sensory integration approach. The American Journal of 
Occupational Therapy. 2001; 55: 285-294.

20. Dunn W. Sensory Profile. The Psychological Corporation: United States of America; 1999.

21. Sigelman C, Life-span human development. Pacific Grove, CA: Brookes/Cole Publishing; 1999.

22. Smyth MM \& Anderson HI. Coping with clumsiness in the school playground: Social and physical play in children with coordination impairments. British Journal of Developmental Psychology. 2000; 18: 389-413.

23. Poulsen AA \& Ziviani JM. Can I play too? Physical activity engagement of children with developmental coordination disorders. The Canadian Journal of Occupational Therapy. 2004; 71:100-107.

24. Bober SJ, Humphry R, Carswell HW \& Core AJ. Toddlers' persistence in the emerging occupations of functional play and self-feeding. The American Journal of Occupational Therapy. 2001; 55: 369-376. 